\title{
LIMITED EFFECT OF REACTIVE OXYGEN SPECIES ON THE COMPOSITION OF SUSCEPTIBLE ESSENTIAL AMINO ACIDS IN THE MIDGUTS OF Lymantria Dispar CATERPILLARS
}

Raymond V. Barbehenn, Julie Niewiadomski, and Joseph Kochmanski

Department of Molecular, Cellular and Developmental Biology, University of Michigan, Ann Arbor, Michigan

Department of Ecology and Evolutionary Biology, University of Michigan, Ann Arbor, Michigan

\section{Peter Constabel}

Centre for Forest Biology and Department of Biology, University of Victoria, Victoria, BC, Canada

The essential amino acids (EAAs) arginine, histidine, lysine, and methionine, as well as cysteine (semiessential), are believed to be susceptible to reactions with reactive oxygen species (ROS) in biological systems. The decreased availability of these EAAs could harm insect nutrition, since several of them can also be limiting for protein synthesis. However, no in vivo studies have quantified the effect of ROS in the midguts of insect herbivores on EAA composition. This study examined the association between elevated levels of ROS in the midgut fluid of Lymantria dispar caterpillars and the compositions of EAAs (protein-bound + protein-free) in their midgut fluid and frass. Contrary to expectation, the compositions of EAAs were not significantly decreased by ROS in midgut fluid ex vivo when incubated with phenolic compounds. Two in vivo comparisons of

\footnotetext{
Grant sponsor: National Research Initiative of the USDA Cooperative State Research, Education and Extension Service; Grant numbers: 2004-35302-14840 and 2007-35302-17803.

Correspondence to: Raymond V. Barbehenn, Department of Molecular, Cellular and Developmental Biology, University of Michigan, Ann Arbor, MI 48109-1048. E-mail: rvb@umich.edu
} 


\begin{abstract}
low- and high-ROS-producing leaves also showed similar results: there were no significant decreases in the compositions of EAAs in the midgut fluids and/or frass of larvae with elevated levels of ROS in their midguts. In addition, waste nitrogen excretion was not significantly increased from larvae on high-ROS treatments, as would be expected if ROS produced unbalanced EAA compositions. These results suggest that L. dispar larvae are able to tolerate elevated levels of ROS in their midguts without nutritionally significant changes in the compositions of susceptible EAAs in their food. (C) 2012 Wiley Periodicals, Inc.
\end{abstract}

Keywords: amino acids; protein; reactive oxygen species; tannin; oxidation; herbivore; nutrition

\title{
INTRODUCTION
}

For plant-feeding insects, protein is commonly considered to be the macronutrient that most strongly affects their growth rates (Mattson, 1980). The foliar protein in most undomesticated plants has a relatively well-balanced essential amino acid (EAA) composition for humans and a variety of plant-feeding animals (Byers, 1971; Sheen, 1991; Yeoh et al., 1992; van Zyl and Ferreira, 2003). Nevertheless, the nutritional quality of this protein is limited (at least for some studied caterpillars) by its low content of histidine (His) and methionine (Met), and to a lesser extent, lysine (Lys), and arginine (Arg) (Rock, 1972; Barbehenn et al., unreported data). When the first limiting amino acid is exhausted in the tissues of an herbivore, it is unable to efficiently utilize the remaining amino acids for protein synthesis, and the excess amino acids must be metabolized and excreted (Horie and Watanabe, 1983). Thus, any decrease in the compositions of the limiting EAAs would potentially decrease the growth rates and fitness of herbivores (Broadway and Duffey, 1988; Karowe and Martin, 1989). Protein that has been allowed to react with reactive oxygen species (ROS) in vitro can have decreased nutritional quality for caterpillars (Felton et al., 1992). It is also well known that ROS can decrease the composition of EAAs in damaged plant tissues (Hurrell et al., 1982; Pierpoint, 1983; Hurrell and Finot, 1984; Schilling et al., 2008). This study was aimed at understanding whether these reactions occur extensively inside the guts of herbivores, such as caterpillars.

Tree-feeding caterpillars can have particularly high levels of ROS in their midguts, since the large amounts of tannins and other phenolic compounds ingested by these insects are prone to oxidize in the high $\mathrm{pH}$ of the midgut (ca. $\mathrm{pH} \mathrm{10).} \mathrm{Oxidizing}$ phenolic compounds produce a variety of ROS in the guts of caterpillars, including semiquinone radicals and quinones (Fig. 1), as well as peroxides (hydrogen peroxide and $\mathrm{ROOH}$ ), superoxide anion radical, and hydroxyl radical (Barbehenn et al., 2001, 2005a,b; Krishnan et al., 2007). Arg, His, Lys, and Met are believed to be especially susceptible to alkylation by quinones or oxidation by other ROS (Felton, 1996). Cysteine, often considered a "semiessential" amino acid, contains a sulfhydryl group that is also expected to react readily with quinones or other ROS (e.g., Quideau et al., 1995). However, no work has quantified the effects of ROS on the compositions of EAAs in the guts of insect herbivores. Therefore, the nutritional importance of these reactions remains unknown. 
<smiles>[R]C(=O)c1cc(O)c(O)c(O)c1</smiles>

Phenolic compound

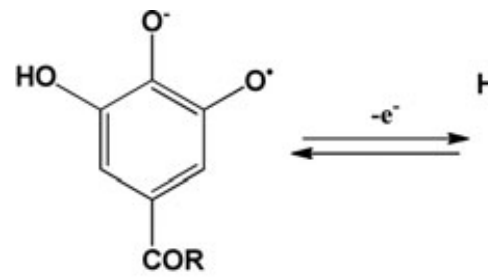

Semiquinone radical<smiles>[R]OC(=O)C1=CC(=O)C(=O)C(O)=C1</smiles>

Quinone

Figure 1. Oxidation of phenolic compounds to semiquinone radicals and quinones.

The effects of ROS on the compositions of Arg, His, Lys, Met, and Cys can be seen in the results of previous in vitro studies (Fig. 2). These results are mixed, showing that different amino acids may be more or less affected in different reaction mixtures. The rate and extent of reactions with amino acids depend upon factors such as $\mathrm{pH}$, oxygen level, reaction time, and the concentrations and types of proteins, amino acids, oxidases, and their substrates (e.g., Hurrell et al., 1982; Hurrell and Finot, 1984; Igarashi and Yasui, 1985; Felton et al., 1989a,b). Generally, the moderate pHs and ambient oxygen levels of reaction mixtures have not modeled the reaction conditions found in the midguts of caterpillars, which have high $\mathrm{pH}$ and low oxygen levels (Johnson and Barbehenn, 2000), as well as a complex mixture of foliar compounds.

The strategy of this study was to bypass two difficulties that have slowed work in this area. First, the identification and quantification of the many products potentially formed by reactions between ROS and each of the susceptible EAAs in an insect's midgut fluid is a daunting task, even with the use of high performance liquid chromatography-mass spectrometry (HPLC-MS) methods (e.g., Matheis and Whitaker, 1984; Quideau et al., 1995; Awad et al., 2000). Second, the absorption of amino acids by insect herbivores is only partially understood. Work done on Bombyx mori caterpillars in vivo indicates that amino acids are absorbed from the midgut lumen primarily in the form of short peptides (Horie and Watanabe, 1982; Shinbo et al., 1996). In this case, there would be no specificity for the amino acids absorbed. By contrast, in vitro studies of amino acid uptake by midgut epithelia have shown that membrane-bound uniporters (passive transport) and symporters (active transport) can facilitate the uptake of some amino acids (Wolfersberger, 2000). Therefore, we chose to use several indirect approaches to examine whether the reactions between ROS and EAAs have a nutritionally significant effect on the compositions of susceptible EAAs.

The potential complexity of EAA absorption can be avoided by using midgut fluid to prepare reaction mixtures with either low or high ROS levels. Thus, the effects of ROS on EAAs were measured in this study in a realistic, low oxygen chemical environment. If nutritionally significant losses of Arg, His, Lys, Met, and/or Cys occurred in high-ROS midgut fluid, then the compositions of these amino acids would be decreased, as seen in several in vitro studies in Figure 2.

Depending on which form of amino acid absorption predominates in caterpillars, we hypothesized that one of three outcomes might be observed in response to increased rates of reaction between ROS and EAAs in the midgut. First, if amino acids were absorbed nonselectively as small peptides, and susceptible EAAs in these peptides reacted with ROS, then the resulting imbalance in EAA composition would produce an excess of absorbed amino acids (unutilizable for protein synthesis). Excess amino acids would be 

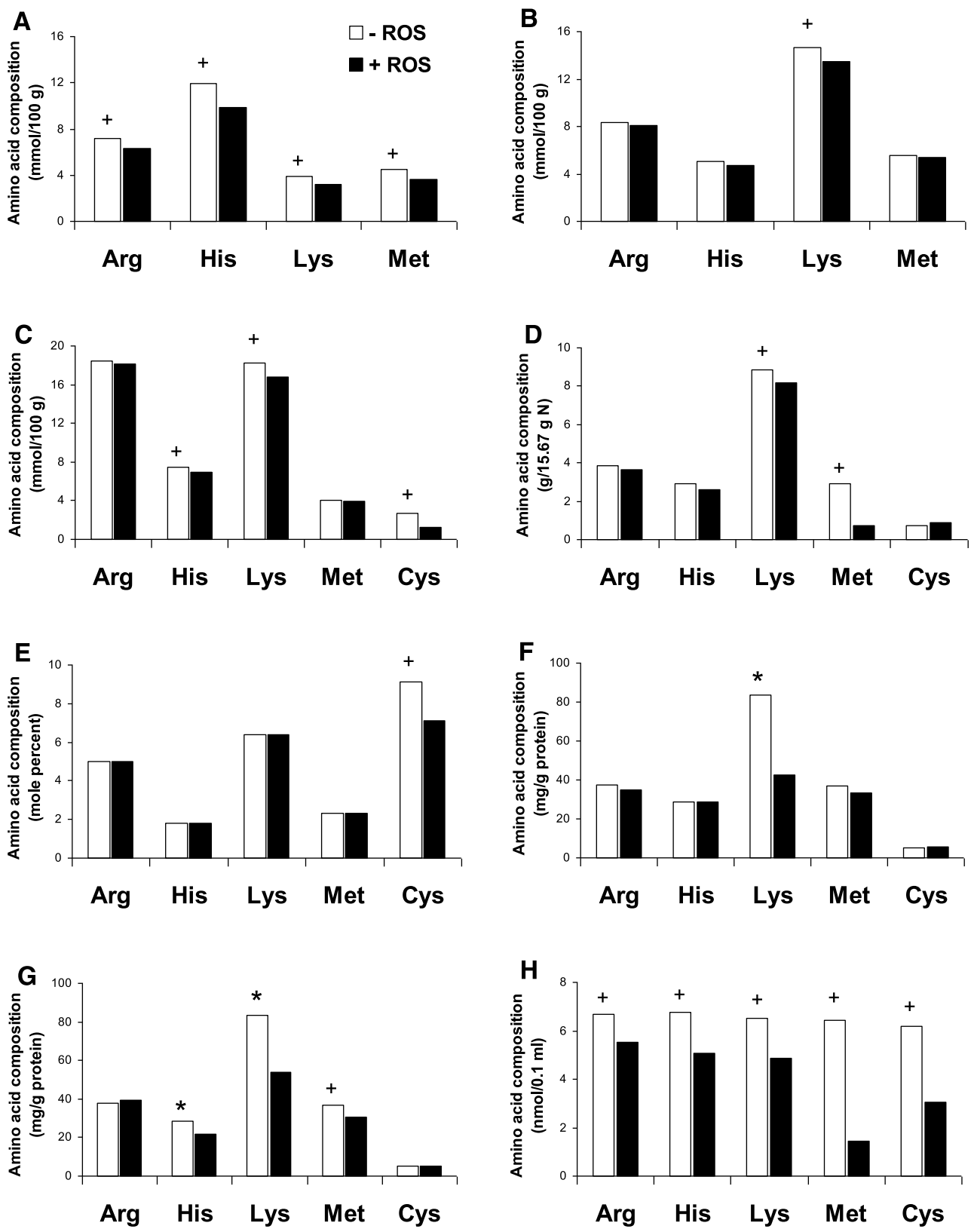

Figure 2. Effect of reactive oxygen species (ROS) on the compositions of Arg, His, Lys, Met, and/or Cys (protein-bound + protein-free) in reaction mixtures. (A) Tomato protein and free amino acids, polyphenol oxidase (PPO), and chlorogenic acid (Felton et al., 1989a). (B) Tomato protein, PPO, and chlorogenic acid (Felton et al., 1989a). (C) Viral protein coat, PPO, and chlorogenic acid (Felton and Duffey, 1990). (D) Casein and caffeic acid (Igarashi and Yasui, 1985). (E) Soybean trypsin inhibitor, PPO, and chlorogenic acid (Felton et al. 1989b). (F) Casein and caffeic acid (Hurrell et al., 1982). (G) Casein, PPO, and caffeic acid (Hurrell et al., 1982). (H) Free amino acids and quercetin (Igarashi and Yasui, 1985). No statistical comparisons were possible in most studies due to low sample size. ${ }^{*}, P<0.05$. + , an effect that the authors considered noteworthy. 
metabolized, increasing the excretion of waste nitrogen products (e.g., uric acid and ammonium salts). Second, larvae might be able to compensate for ROS reactions with EAAs by digesting protein and absorbing peptides more efficiently (Felton, 1996). This response would increase the assimilation efficiencies of total amino acids. It would also result in the excretion of increased amounts of waste nitrogen products, since the excess absorbed amino acids could not be used for protein synthesis if certain EAAs were in short supply. Finally, if herbivores compensated for increased ROS reactions with EAAs by increasing the absorption of these specific EAAs, then both an increase in absorption rate and a decrease in EAA levels from ROS reactions would decrease the compositions of these EAAs in the midgut lumen and frass. In this case, the impact on waste nitrogen products would be minimized, since larvae would be able to maintain a better balance of absorbed EAAs. If there was a lack of support for each of these hypotheses, we would be unable to reject the null hypothesis, suggesting that ROS have no nutritionally significant impact on susceptible EAAs in the midgut lumen of the test species.

Tests of the above hypotheses were made with Lymantria dispar L. (gypsy moth), a widely polyphagous caterpillar. Its host range in the eastern United States includes red oak (Quercus rubra L.) and sugar maple (Acer saccharum Marsh.), which were two tree species compared in this study. Red oak is a highly preferred host plant that produces low levels of ROS in the midguts of caterpillars (Liebhold et al., 1995; Barbehenn et al., 2008). By contrast, sugar maple is a relatively poor host plant that contains high levels of ellagitannins. Ellagitannins autoxidize rapidly at the high $\mathrm{pH}$ in the midguts of caterpillars, producing high levels of ROS (Barbehenn et al., 2008). Therefore, it was expected that susceptible EAAs would be depleted more by reactions with ROS in the midguts of larvae that fed on maple than on oak.

An independent set of comparisons was made using $L$. dispar larvae that fed on lowROS- or high-ROS-producing poplar (Populus tremula $\times$ P. alba) leaves. Elevated ROS levels were produced in the midguts of larvae that fed on the induced (i.e., insect damaged) leaves of a peroxidase (POD) overexpressing genotype (Barbehenn et al., 2010). Elevated levels of ROS were also associated with decreased larval growth rates. Therefore, in both sets of experiments, we wished to determine whether a decrease in the availability of limiting EAAs might explain the decrease in growth rates of larvae on high-ROS-producing leaves.

In both sets of experiments, we measured the percentage of ingested EAAs that were egested, which would be expected to decrease if assimilation efficiencies and/or ROS reactions with EAAs increased. Finally, we compared the levels of waste nitrogen products in the frass of larvae from low- and high-ROS treatments, with the expectation that waste nitrogen levels should increase from insects on high-ROS treatments if ROS reactions with EAAs produced nutritionally significant decreases in EAA compositions in the midgut.

\section{MATERIALS AND METHODS}

\section{Effects of ROS on EAAs in Midgut Fluid Reaction Mixtures}

Midgut fluid for reaction mixtures was collected from final-instar L. disparlarvae on poplar leaves. These larvae were reared from eggs obtained from the United States Department of Agriculture (Otis Air Force Base, MA). They initially fed on an artificial diet in Petri dishes in an incubator, primarily at $23^{\circ} \mathrm{C}$ with a 16 -h photoperiod (Barbehenn et al., 2009a). Final-instar larvae were fed wild-type poplar leaves for 2 days. On the third day, 
they were chilled for $6 \mathrm{~min}$ at $-20^{\circ} \mathrm{C}$ and dissected, removing the entire gut. The midgut contents of approximately 45 larvae were collected in $2.0 \mathrm{ml}$ centrifuge tubes, which were kept flushed with nitrogen and on ice during dissection. Samples were stored at $-80^{\circ} \mathrm{C}$ until the midgut fluid was separated by centrifugation $\left(8,000 \times g, 4^{\circ} \mathrm{C}, 5 \mathrm{~min}\right)$. The separated midgut fluid was pooled and maintained under a nitrogen atmosphere on ice. The pellets remaining after removal of the supernatant solution were mixed with an additional 200-250 $\mu$ l of low oxygen double-distilled water. After centrifugation, all supernatant solutions were combined. The final midgut fluid preparation (particle-free) was at approximately $75 \%$ of its original concentration. Because hybrid poplar leaves contain negligible levels of tannins and only $1 \%$ (dry weight [DW]) of low molecular weight phenolic compounds, the control midgut fluid was expected to be essentially ROS free (Barbehenn et al., 2009b).

Reaction mixtures ( $n=7$ control and 8 phenol treated) were prepared by placing $45-\mu l$ aliquots of midgut fluid in centrifuge tubes along with either $5 \mu$ l of low oxygen double-distilled water (control) or $5 \mu \mathrm{l}$ of a low oxygen phenolic solution. The phenolic solution was prepared with ellagitannins $(106 \mathrm{mg} / \mathrm{ml})$ and chlorogenic acid $(26 \mathrm{mg} / \mathrm{ml})$ in acidified low oxygen double-distilled water. The ellagitannin mixture was purified from Lythrum salicaria (Moilanen and Salminen, 2008). Chlorogenic acid (Sigma Chemical Co., St. Louis, MO) is a low molecular weight phenolic compound found widely in plants, including tree leaves. The concentration of each phenolic was calculated to produce a high level of ROS in the midgut fluid $L$. dispar larvae (Barbehenn et al., 2010). Following a 1-h incubation period $\left(23^{\circ} \mathrm{C}\right)$, each reaction mixture was pipetted into $0.625 \mathrm{ml}$ of $6 \mathrm{M}$ $\mathrm{HCl}$ (anaerobic, containing $5 \%$ dithiodipropionic acid and $0.06 \%$ phenol). Samples were hydrolyzed, and their amino acid compositions were measured with HPLC, as described below. The amounts of susceptible EAAs in the samples (free + protein bound) were expressed in terms of composition ( $\mathrm{mg} / \mathrm{g}$ total amino acids) and concentration $(\mathrm{mg} / \mathrm{ml})$.

\section{Effects of Oak (Low ROS) versus Maple (High ROS) on EAAs in Vivo}

Midgut fluid (particle free) was collected separately from individual fourth-instar larvae that fed on either oak or maple leaves. Leaf clusters on twigs were cut from oak and maple trees ( $n=3-4$ trees/species) in mid-May, as described previously (Barbehenn et al., 2009a). The leaves were washed with a sponge under water, and the twigs were placed in tubes of water in plastic shoeboxes. Newly molted fourth-instar larvae were placed at random on the oak or maple leaves $(n=12-13$ replicate larvae/tree species). Larvae fed for 2 days in an incubator $\left(23^{\circ} \mathrm{C}\right.$, 16-h light), with fresh leaves provided on the second day. On the third day, individual larvae were dissected, as described above. The midgut contents of each larva were placed in tared 2-ml centrifuge tubes containing $300 \mu \mathrm{l}$ of nitrogen-purged potassium phosphate buffer $(\mathrm{pH} 6.0,0.1 \mathrm{M})$. The headspace of each tube was purged with nitrogen, and its contents were dispersed in the buffer and weighed. Samples were stored at $-80^{\circ} \mathrm{C}$. Thawed samples were mixed and centrifuged $\left(8000 \times g, 3 \mathrm{~min}, 4^{\circ} \mathrm{C}\right)$. Aliquots $(100 \mu \mathrm{l})$ of the supernatant solutions were hydrolyzed and analyzed for amino acids, as described above.

Midgut fluid was ultrafiltered to estimate the fraction of the total amino acids that was present as protein $(>10,000$ molecular weight cut off [MWCO]), or peptides $(<10,000$ MWCO), or free amino acids. Fourth-instar $L$. dispar larvae were fed either red oak or sugar maple leaves for a 3-day period. The midguts (anterior halves) of each larva ( $n=9$ /tree species) were dissected, weighed, and extracted in $400 \mu \mathrm{l}$ of nitrogen-purged potassium phosphate buffer $(\mathrm{pH} 6.0,0.1 \mathrm{M})$. After centrifugation $\left(8,000 \times g, 5 \mathrm{~min}, 4^{\circ} \mathrm{C}\right)$, 
a $120-\mu 1$ aliquot of each supernatant solution was centrifuged in a nitrogen-flushed ultrafilter (Amicon Ultra $0.5 ; 10,000 \mathrm{MWCO}$ ). The total amino acid contents of three fractions were measured with HPLC from each larva: (1) unfiltered midgut fluid (hydrolyzed, measuring total amino acids), (2) ultrafiltered midgut fluid (hydrolyzed, measuring polypeptides and free amino acids), and (3) ultrafiltered midgut fluid (unhydrolyzed, measuring free amino acids).

To compare the effects of feeding on oak or maple leaves on ingested EAAs, a quantitative feeding experiment was performed, and the Arg, His, Lys, and Met compositions of the leaves and frass were measured. Newly molted fourth-instar larvae $(n=10-12 /$ tree species) were randomly assigned to feed on oak or maple leaves in mid-May. To accurately measure consumption, weighed leaf disks $(2.5 \mathrm{~cm}$ diameter $)$ were provided to each larva, using amounts that were largely consumed each day. The disks were cut with a cork borer from freshly collected, washed leaves. Larvae were kept individually in 35-ml plastic cups in an incubator $\left(23^{\circ} \mathrm{C}\right.$, 16-h light). Each larva was fed fresh food daily, and a moistened filter paper disk was placed in the bottom of each cup to maintain leaf turgidity. Uneaten food and frass were removed daily and weighed after drying $\left(70^{\circ} \mathrm{C}\right)$. DWs of food were calculated based on the \% DW of five representative leaf disks. Larvae were fed for the duration of the fourth instar (5-7 days). The amino acids in leaf samples from each day and in the frass from each larva were quantified with HPLC, as described below. The amounts of ingested Arg, His, Lys, and Met were calculated as (\%DW of amino acid in the leaves) $\times$ (total milligram of leaves ingested). The amounts of egested Arg, His, Lys, and Met were calculated as $(\% \mathrm{DW}$ of amino acid in the frass $) \times$ (total milligram frass produced). The percentages of egested/ingested EAAs were calculated and compared between larvae on oak and maple. This method avoided the confounding effect of different protein levels in oak and maple leaves on comparisons of EAAs in midgut fluids and frass. Specifically, larvae on oak ingested larger amounts of Arg, His, Lys, and Met since there was a higher concentration of total amino acids in oak leaves $(16.4 \pm 0.4 \% \mathrm{DW})$ than in maple leaves $(12.7 \pm 0.5 \%)(P<0.05)$. The percentages of egested/ingested EAAs were expected to be lower from maple- than oak-feeding larvae, if susceptible EAAs were negatively impacted by ROS and/or absorbed more efficiently from maple. The assimilation efficiencies for total amino acids were calculated as (milligram amino acids ingested) / (milligram amino acids ingested - milligram amino acids egested) $\times 100$. Waste nitrogen products (uric acid and ammonium salts) in the frass of larvae on each of the tree species were also quantified, as described below. Increased levels of waste nitrogen products from maplefeeding larvae would be consistent with the hypothesis that ROS depleted the levels of susceptible EAAs, creating an imbalanced EAA composition.

\section{Effects of High-ROS-Producing Poplar on EAAs in Vivo}

A quantitative feeding experiment was performed with fourth-instar $L$. dispar larvae on poplar leaves, as described above, but with the following changes. Hybrid poplar was genetically modified to overexpress horseradish POD, and saplings were grown in a greenhouse (Barbehenn et al., 2010). Saplings of the untransformed (wild type) poplar and three independently transformed lines were grown in 8-1 pots to a height of 2-3 m. Newly molted fourth-instar $L$. dispar larvae were randomly assigned to one of four treatments $(n=7$ larvae/treatment): undamaged untransformed leaves (wild type), induced untransformed leaves, undamaged POD-overexpressing leaves, or induced POD-overexpressing leaves. Three replicate saplings per line were used for each treatment. Leaves were induced by a pair of fourth-instar larvae that fed on them for a 24 -h period inside a 
mesh bag. Undamaged (control) leaves of each line were covered with a mesh bag without larvae. Leaves from positions 15-20 (counting radially down from the first unfolded leaf) were used for food, with one leaf harvested per sapling per day from each line. Leaves were removed from saplings with a sterile razor blade and promptly cut with a cork borer into disks $(2.5 \mathrm{~cm}$ diameter $)$. Leaf disks were mixed within treatment groups to randomize any between-line variation. Due to the unusually low levels of phenolic compounds in the greenhouse-grown poplar leaves (Barbehenn et al., 2010), all disks were treated with $20 \mu \mathrm{l}$ of a $70 \%$ acetone solution of chlorogenic acid (increasing its level to approximately $6 \% \mathrm{DW})$. The additional chlorogenic acid provided ample substrate for the ingested POD. Leaf samples ( $n=5$ replicate dates/treatment) and frass samples $(n=7$ replicate larvae/treatment) were dried and analyzed for amino acids as described above. The percentages of egested/ingested Arg, His, Lys, and Met, and the assimilation efficiencies of total amino acids were calculated as described above. Waste nitrogen products in the frass of larvae from each of the four treatments were also measured. It was expected that larvae on induced POD-overexpressing leaves would have lower percentages of egested/ingested EAAs and increased waste nitrogen products compared with larvae on each of the other three treatments, if ROS had nutritionally significant effects on levels of these EAAs.

\section{Amino Acid Analysis}

Dried leaf and frass samples were ground to a powder with a dental amalgamator (Zenith, American Dental, Minneapolis, MN). Samples (2-4 mg) were weighed and placed in pressure-resistant 7-ml vials (Thermo Fisher Scientific, Pittsburg, PA) with open-center caps and Tuf-Bond teflon/silicon septa in $1.25 \mathrm{ml}$ of nitrogen-purged $6 \mathrm{M} \mathrm{HCl}$. Vials were flushed with nitrogen, and samples were hydrolyzed for $24 \mathrm{~h}$ at $110^{\circ} \mathrm{C}$. An equal volume of $6 \mathrm{M} \mathrm{NaOH}$ was added to the hydrolyzed samples. The fluorescent label 6-aminoquinolylN-hydroxysuccinimidyl carbamate (AQC) was synthesized, as described by Cohen and Michaud (1983). An aliquot $(50 \mu \mathrm{l})$ of the neutralized hydrolysate was mixed with $50 \mu \mathrm{l}$ of $0.5 \mathrm{M}$ borate buffer ( $\mathrm{pH} 8.8$ ), and derivatized with $26.4 \mu \mathrm{l}$ of an AQC solution $(10 \mathrm{mM})$ in acetonitrile. An aliquot $(30 \mu \mathrm{l})$ of each filtered sample or standard was analyzed with HPLC (Cohen and Michaud, 1983). Amino acid derivatives were separated on a Supelco Discovery HS C18 column $(5.0 \mu \mathrm{m}, 250 \mathrm{~mm} \times 4.6 \mathrm{~mm})$ with a C18 guard column. The gradient used was initially $100 \%$ A (pH 5.05 acetate buffer) $/ 0 \%$ B (60\% aqueous acetonitrile), increasing to $2 \% \mathrm{~B}$ at $0.5 \mathrm{~min}, 7 \% \mathrm{~B}$ at $15 \mathrm{~min}, 13 \% \mathrm{~B}$ at $19 \mathrm{~min}, 28 \% \mathrm{~B}$ at $28 \mathrm{~min}, 45 \% \mathrm{~B}$ at $38 \mathrm{~min}$, and returning to $0 \% \mathrm{~B}$ at $43 \mathrm{~min}$. The flow rate was $1.0 \mathrm{ml} / \mathrm{min}$ and the column temperature was $35^{\circ} \mathrm{C}$. Peaks were detected with a Shimadzu RF-535 fluorescence detector (Shimadzu, Columbia, MD) at $250 \mathrm{~nm}$ excitation/395 nm emission wavelengths. Individual amino acids were purchased for preparing their standard curves (Sigma Chemical Co.). We quantified 17 amino acids. Trp and Cys are destroyed during standard HCl hydrolysis, and Asn and Gln are converted to Asp and Glu. To measure Cys, a subset of the samples was re-hydrolyzed with $5 \%(\mathrm{w} / \mathrm{v})$ dithiodipropionic acid and $0.06 \%$ phenol (Strydom and Cohen, 1993). Dithiodipropionic acid interfered with the measurement of Met, and was only used where specified. Amino acid composition was calculated as (milligram individual amino acid) /(milligram total amino acids) $\times 100$, where total amino acids included those that were free or protein-bound.

Because EAA composition is a relative measure (i.e., changes in one amino acid affect the compositions of others), we modeled the effect of the complete removal of an abundant amino acid (Phe) on the compositions of the remaining amino acids in oak leaf protein. This large change in amino acid composition resulted in only an $8 \%$ average 
increase in the compositions of the remaining 16 measured amino acids. Therefore, the indirect effects of changes in amino acid levels on the compositions of susceptible EAAs appear to be minimal in this study.

\section{Waste Nitrogen Products}

Dried frass from larvae in the quantitative feeding experiments was analyzed for two major waste nitrogen products. Uric acid was extracted from ground frass samples (10 $\mathrm{mg})$ in $500 \mu \mathrm{l}$ of $\mathrm{pH} 2.1$ buffer (containing $10 \mathrm{mg}$ polyvinylpolypyrrolidone) at $60^{\circ} \mathrm{C}$ for $30 \mathrm{~min}$ (Shingfield and Offer, 1999). Frass samples from 5-12 replicate larvae per treatment were analyzed. Uric acid was measured with a Waters 2690 Separations Module HPLC, coupled with a Waters 996 photodiode array detector. Uric acid was separated with a pair of connected columns: a Metachem Polaris C18 $(3.0 \mu \mathrm{m}, 150 \mathrm{~mm} \times 4.6 \mathrm{~mm})$ and an Agilent Zorbax Bonus-RP C14 (3.5 um, $150 \mathrm{~mm} \times 4.6 \mathrm{~mm})$ with a C18 guard column. A pH 3.0 buffer was used as the mobile phase $\left(1.0 \mathrm{ml} / \mathrm{min}, 40^{\circ} \mathrm{C}\right.$ ) (Shingfield and Offer, 1999). Uric acid was identified based on its peak retention time and UV-visible spectrum compared with uric acid standards. Two other waste nitrogen products produced by some Lepidoptera, allantoin and allantoic acid, were not found in the frass.

Ammonia, found in the frass as an ammonium salt (Lovett et al., 1998), was measured in acid hydrolysates with HPLC along with the amino acids (Cohen and Michaud, 1983). A standard curve was prepared from a commercial solution of ammonia ( $7 \mathrm{~N}$; Sigma Chemical Co.). The amount of ammonia measured in the frass was corrected for ammonia produced by the hydrolysis of uric acid and the hydrolysis of protein. For each of these sources, a regression of amount of the substance versus the amount of ammonia in hydrolysates was produced. The amount of ammonia from each source was then calculated from the amount of uric acid or protein (total amino acids) measured in the frass, and subtracted from the total ammonia measured. Purified tobacco leaf protein (fraction 1; primarily RuBisCO) was used as the test protein.

\section{Statistical Analysis}

The composition of Arg, Lys, His, Met, and/or Cys in midgut fluids, tree leaves, and frass were compared with separate one-way analysis of variance (ANOVA) on each amino acid (SAS, 2003). The same analysis was also used to compare the percentages of egested/ingested Arg, Lys, His, and Met from larvae on oak or maple, total amino acid assimilation efficiencies, and the levels of uric acid and ammonia in the frass. The results of experiments on larvae on hybrid poplar leaves were analyzed using ANOVA with contrasts between induced POD-overexpressing poplar and the other three treatments (SAS, 2003). Multiple comparisons between treatment means were made using differences of least-squares means with PROC MIXED (SAS, 2003). These comparisons tested a priori hypotheses, requiring no post hoc adjustment for multiple comparisons. The normality of residuals was tested with PROC MIXED, and data were transformed where necessary.

\section{RESULTS}

\section{Effects of ROS on EAAs in Midgut Fluid Reaction Mixtures}

As expected, ex vivo reaction mixtures that were treated with phenolic compounds became increasingly brown during the 1 -h reaction, consistent with the formation of ROS 

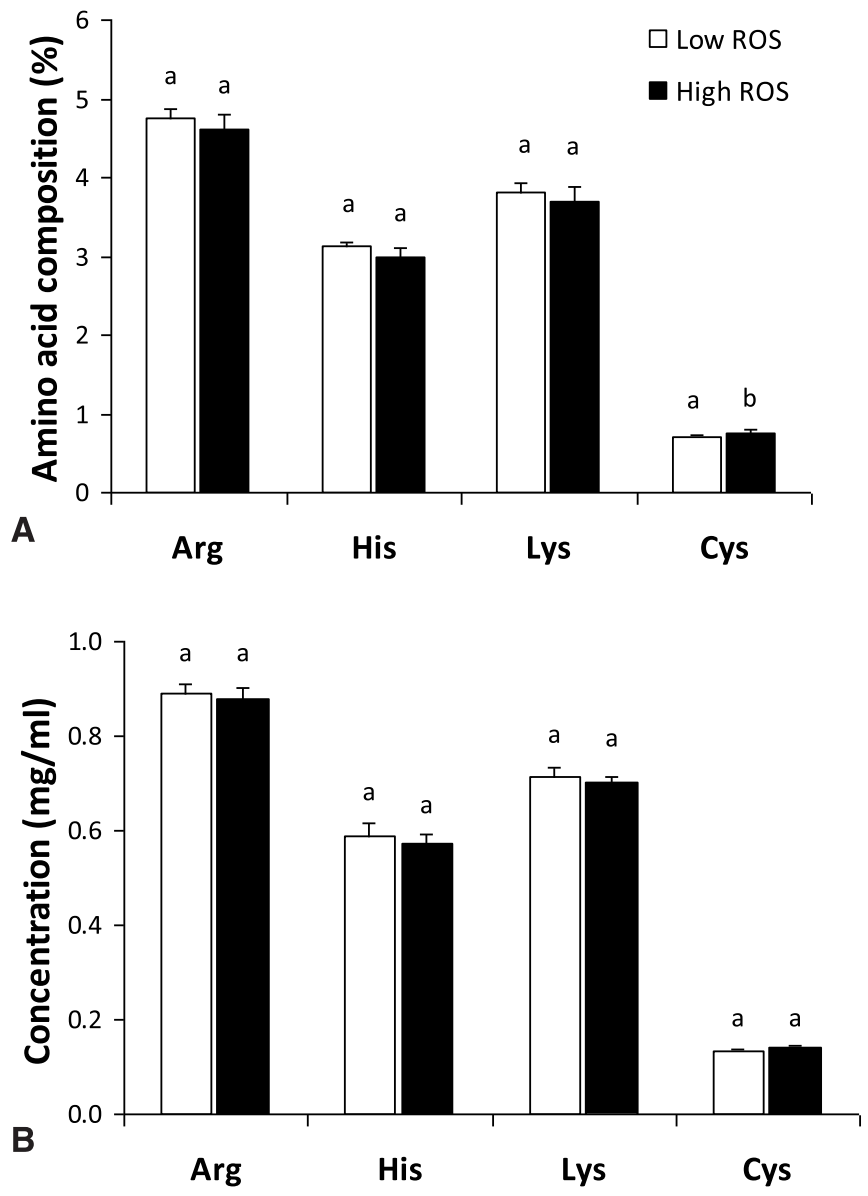

Figure 3. Compositions $(\mathrm{mg} / \mathrm{g}$ total amino acids $\times 100)(\mathrm{A})$ and concentrations $(\mathrm{B})$ of Arg, His, Lys, and Cys (protein-bound + protein-free) in midgut fluid reaction mixtures. Midgut fluid from Lymantria dispar larvae was either spiked with water ("-ROS") (where ROS is reactive oxygen species) or a concentrated mixture of phenolic compounds ("+ROS"), and allowed to react under a nitrogen atmosphere for $1 \mathrm{~h}$. Data are presented as mean \pm SE. Nonoverlapping letters within amino acids indicate significant differences between treatments.

(quinones). No visible browning occurred in untreated midgut fluid. Nevertheless, there were no significant differences between the compositions of Arg, His, Lys, or Cys in treated and untreated midgut fluid (Fig. 3A). Surprisingly, there was a small $(8.8 \%$; $P=0.017)$ increase in the composition of Cys after phenolic treatment. The expression of the results as compositions $(\mathrm{mg} / \mathrm{g}$ total amino acids) or concentrations $(\mathrm{mg} / \mathrm{ml})$ showed the same effect: ROS had no significant impact on the concentrations of the susceptible EAAs measured in the reaction mixtures (Fig. 3B).

\section{Effects of Oak (Low ROS) versus Maple (High ROS) on EAAs in Vivo}

In the midgut fluid of larvae on maple (high ROS), the compositions of Arg, His, Lys, and Met were not decreased relative to those in larvae on oak (low ROS) (Fig. 4B). Surprisingly, the composition of Met was higher, rather than lower, in larvae on maple $(P=0.002)$. The fraction of the total amino acids present as proteins, peptides, or free 

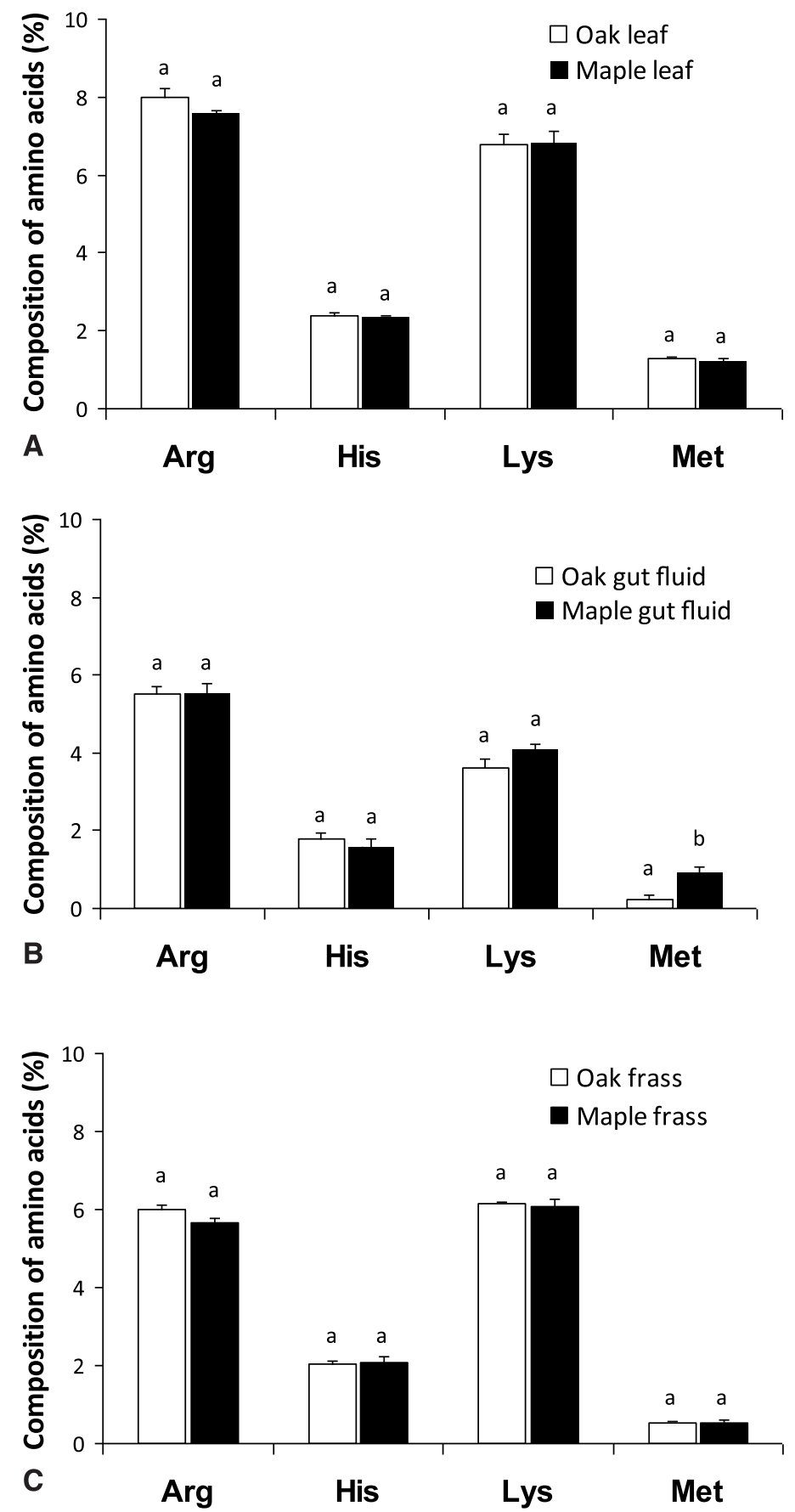

Figure 4. (A) Arg, His, Lys, and Met compositions ( $\mathrm{mg} / \mathrm{g}$ total amino acids $\times 100$ ) of red oak and sugar maple leaves. (B) Essential amino acid (EAA) composition of the midgut fluid from Lymantria dispar larvae that fed on red oak (producing low reactive oxygen species [ROS] levels) or sugar maple (producing high ROS levels). (C) EAA composition of frass from $L$. dispar larvae that fed on red oak or sugar maple. Data are presented as mean $\pm \mathrm{SE}$. Nonoverlapping letters within amino acids indicate significant differences between tree species. 
Table 1. Waste Nitrogen Produced by Lymantria dispar Larvae on Red Oak or Sugar Maple Leaves

\begin{tabular}{lccc}
\hline Species & $\begin{array}{c}\text { Uric acid } \\
(\% D W)\end{array}$ & $\begin{array}{c}\text { Ammonia } \\
(\% D W)\end{array}$ & $\begin{array}{c}\text { Total waste } \\
\text { Nproducts } \\
(\% D W)\end{array}$ \\
\hline Red oak & $0.18 \pm 0.01^{\mathrm{b}}$ & $0.86 \pm 0.05^{\mathrm{a}}$ & $1.04 \pm 0.05^{\mathrm{a}}$ \\
Sugar maple & $0.03 \pm 0.003^{\mathrm{a}}$ & $0.92 \pm 0.03^{\mathrm{a}}$ & $0.95 \pm 0.03^{\mathrm{a}}$ \\
\hline
\end{tabular}

Data are presented as mean \pm SE $(n=5-12)$. Data within columns followed by different letters are significantly different $(P<0.05)$. Ammonium salts in the frass were measured as ammonia in acid hydrolysates.

amino acids in the anterior midgut fluid from larvae on both oak and maple leaves was similar: approximately $40 \%$ was protein bound (i.e., $>10,000 \mathrm{MWCO}$ ), $50 \%$ was peptide bound (i.e., $<10,000 \mathrm{MWCO}$ ), and only $10 \%$ was free amino acids.

The initial Arg, His, Lys, and Met composition of oak and maple leaves did not differ significantly, indicating that there was no bias at the start of the experiment (Fig. 4A). Contrary to expectation, the compositions of susceptible EAAs in the frass were not significantly lower from maple- than from oak-feeding insects (Fig. 4C). When the percentage of egested/ingested EAAs were compared between species, only His was significantly lower (by 14\%) from larvae on maple relative to those on oak (Fig. 6A). The assimilation efficiencies for total amino acids from oak $(78.3 \pm 1.7 \%)$ and maple leaves $(79.7$ $\pm 1.3 \%)$ also were not significantly different $(P=0.331)$. One waste nitrogen product, uric acid, was at lower levels from larvae on maple leaves, the opposite of the pattern expected if larvae absorbed a less balanced EAA mixture from maple leaves due to ROS reactions with EAAs (Table 1). The main waste nitrogen product measured was ammonia, and its level did not differ significantly between tree species. Thus, the total amounts of waste nitrogen measured from larvae that fed on oak or maple were not significantly different.

\section{Effects of Low-ROS- versus High-ROS-Producing Poplar on EAAs in Vivo}

The initial compositions of Arg, His, Lys, and Met in the leaves of wild-type and undamaged POD-overexpressing poplar were similar to those in induced POD-overexpressing poplar (contrast $P$ values $=0.143-0.713$ for the four EAAs) (Fig. 5A). There were no significant changes in the Arg, Lys, and Met compositions in the frass from larvae that fed on induced POD poplar leaves (high-ROS producing) compared with the frass produced from low-ROS-producing leaves (Fig. 5B; contrast $P$ values $=0.555-0.862$ ). The His composition of frass from larvae on induced POD-overexpressing poplar leaves showed a nearly significant decrease (contrast $P=0.052$ ), though in comparison with two of the three other treatments, the quantitative differences were small and nonsignificant. The percentages of egested/ingested Arg, His, Lys, and Met were not significantly decreased by elevated levels of ROS in larvae on induced POD-overexpressing poplar leaves (Fig. 6B, contrast $P$ values $=0.581-0.942$ ). The assimilation efficiencies for total amino acids ranged from an average of 69.1 to $72.9 \%$ for larvae on each of the four leaf treatments (contrast $P=0.633$ ). Surprisingly, uric acid production was lower, rather than higher, in larvae on the induced POD-overexpressing poplar leaves (Table 2). However, the total amounts of waste nitrogen produced by larvae that fed on the low- or high-ROS-producing poplar treatments were not significantly different. 

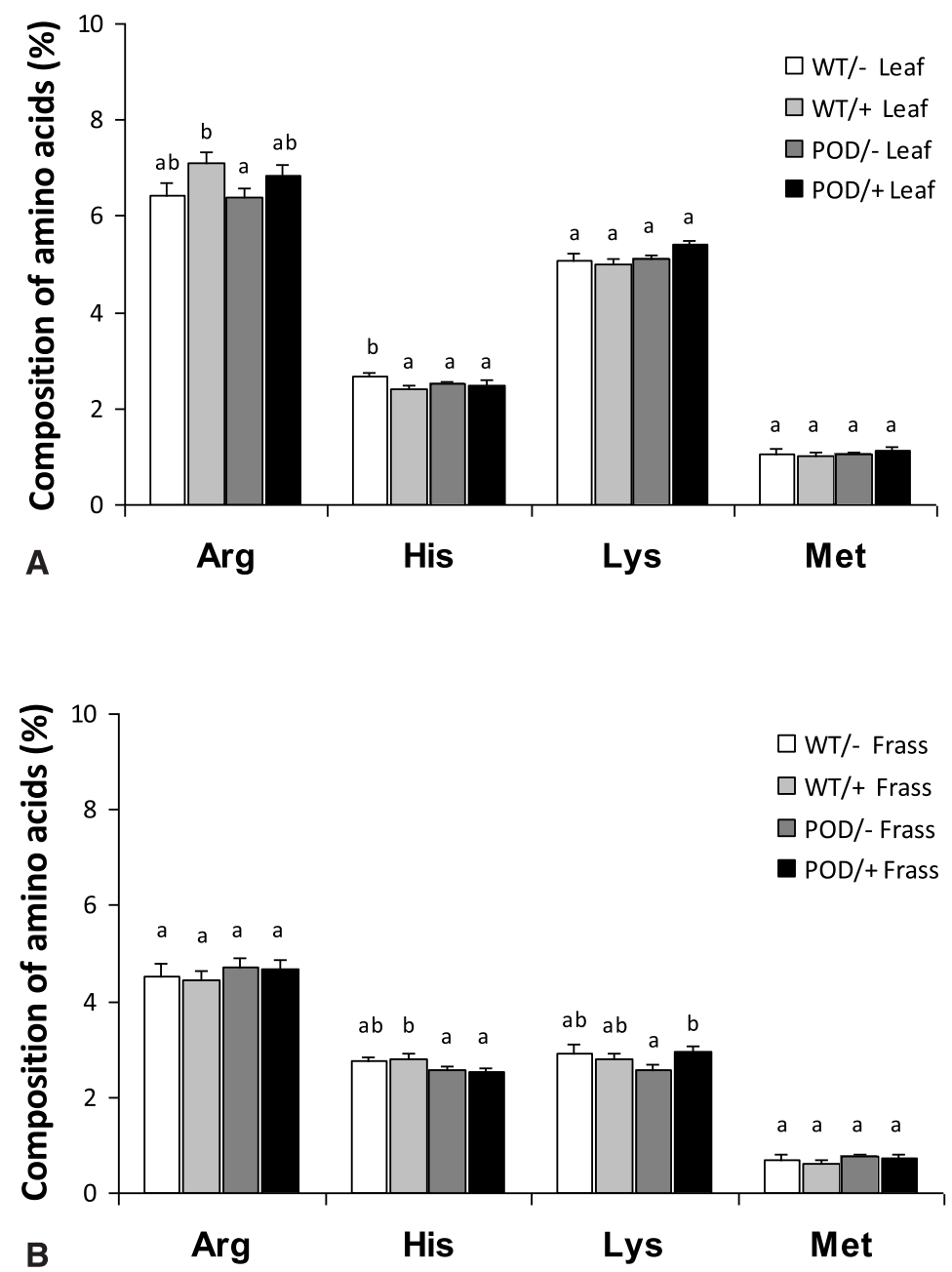

Figure 5. (A) Arg, His, Lys, and Met compositions (mg/g total amino acids $\times 100)$ of hybrid poplar leaves. (B) Essential amino acid (EAA) composition of frass from Lymantria dispar larvae that fed on poplar leaves. WT, wild type (untransformed); POD, peroxidase; -, uninduced; +, induced. Only induced POD-overexpressing leaves produced high levels of reactive oxygen species (ROS) in the midgut. Data are presented as mean $\pm \mathrm{SE}$. Nonoverlapping letters indicate significant differences between treatments within amino acids.

\section{DISCUSSION}

Our work provides the first examination of the effects of ROS on the amino acid composition in the digestive tract of an insect herbivore. Elevated levels of ROS appeared to have little or no effect on the putatively susceptible EAAs in L. disparlarvae. Although it is commonly believed that ROS do have a negative impact on susceptible EAAs in biological systems, much of the support for this view is based on in vitro studies, and their results have been mixed (Fig. 2). Second, in vivo conditions have low oxygen levels and involve the antioxidant defenses of insect herbivores (Felton and Summers, 1995), conditions that were not modeled in previous in vitro studies. When low oxygen midgut fluid was 

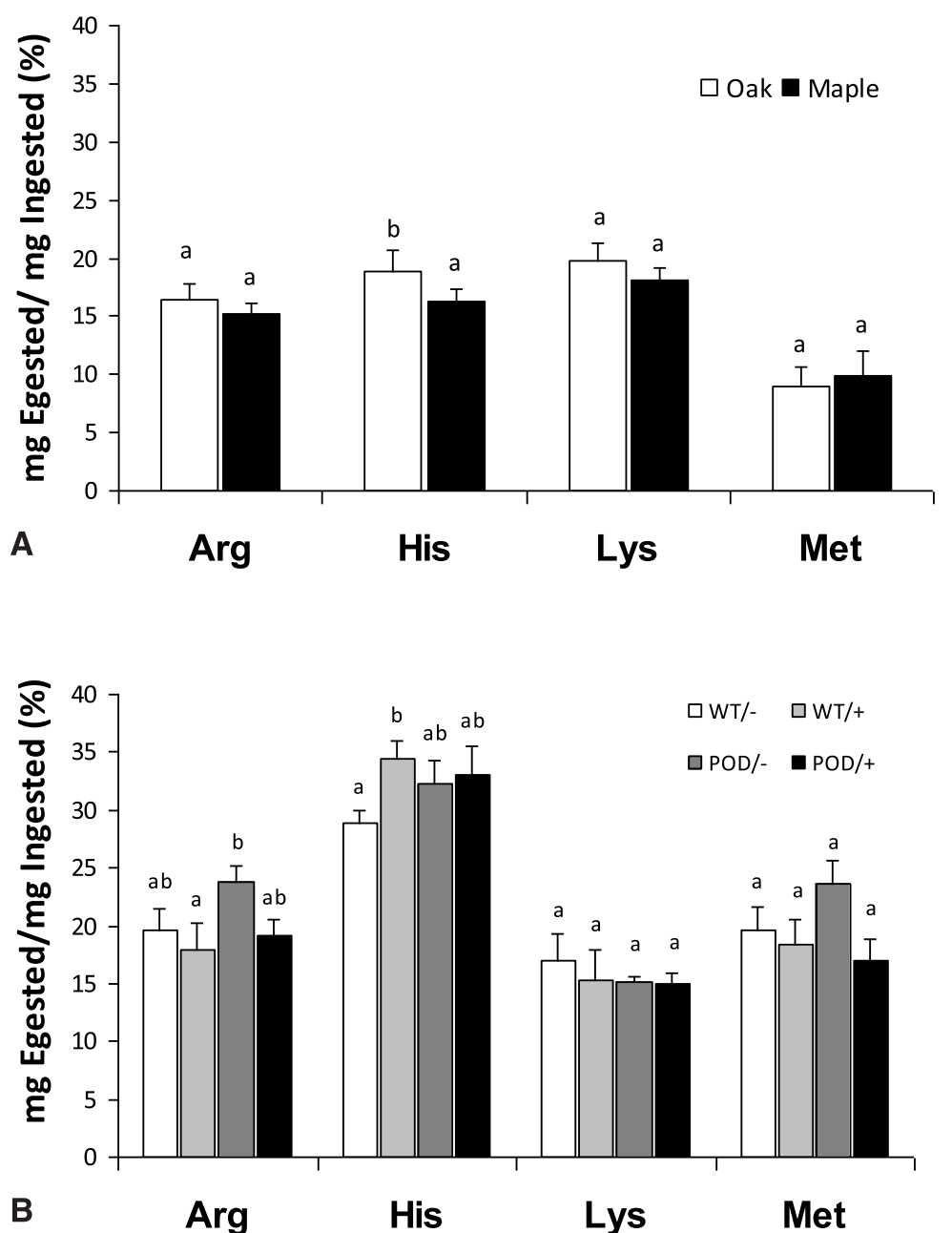

Figure 6. Percentages of ingested Arg, His, Lys, and Met egested in the frass of Lymantria dispar larvae on red oak or sugar maple leaves (A) or hybrid poplar treatments (B). WT, wild type (untransformed); POD, peroxidase; -, uninduced; +, induced. Only induced POD-overexpressing leaves produced high levels of reactive oxygen species (ROS) in the midgut. Data are presented as mean \pm SE. Nonoverlapping letters within amino acids indicate significant differences between treatments.

used as the test medium (ex vivo) in this study, there were no significant effects of ROS on EAAs.

Overall, we found little support for three alternative hypotheses in which ROS decrease the levels of susceptible EAAs in vivo. Contrary to the first hypothesis, the compositions of Arg, His, Lys, and Met were not significantly lower in midgut fluid from larvae on sugar maple (high ROS) than on red oak (low ROS) leaves. Similarly, no decreases in the compositions of EAAs were observed in the frass of larvae that fed on maple, or in the frass of larvae on induced POD-overexpressing poplar leaves (high ROS). Importantly, no increases in waste nitrogen excretion occurred from larvae that fed on any of these high-ROS-producing leaves. Therefore, there was no support for the hypothesis that susceptible EAAs were depleted by ROS, causing larvae to absorb a nutritionally poor amino 
Table 2. Waste Nitrogen Produced by Lymantria dispar Larvae on Wild-Type or Peroxidase-Overexpressing Leaves with or without Induction by Feeding Damage

\begin{tabular}{lcccc}
\hline Genotype & Treatment & $\begin{array}{c}\text { Uric acid } \\
(\% D W)\end{array}$ & $\begin{array}{c}\text { Ammonia } \\
(\% D W)\end{array}$ & $\begin{array}{r}\text { Total waste } \\
\text { Nproducts } \\
(\% D W)\end{array}$ \\
\hline Wild type & Undamaged & $0.82 \pm 0.04^{\mathrm{a}}$ & $1.28 \pm 0.12^{\mathrm{a}}$ & $2.10 \pm 0.10^{\mathrm{a}}$ \\
Wild type & Damaged & $0.91 \pm 0.06^{\mathrm{b}}$ & $1.21 \pm 0.10^{\mathrm{a}}$ & $2.13 \pm 0.09^{\mathrm{a}}$ \\
Transgenic & Undamaged & $0.82 \pm 0.06^{\mathrm{a}}$ & $1.25 \pm 0.08^{\mathrm{a}}$ & $2.06 \pm 0.07^{\mathrm{a}}$ \\
Transgenic & Damaged & $0.74 \pm 0.03^{\mathrm{a}}$ & $1.22 \pm 0.09^{\mathrm{a}}$ & $1.94 \pm 0.08^{\mathrm{a}}$ \\
& & $P=0.018$ & $P=0.688$ & $P=0.097$ \\
\hline
\end{tabular}

Data are presented as mean \pm SE $(n=5-12)$. Data within columns followed by different letters are significantly different $(P<0.05)$ based on differences of least squares means (following one-way ANOVA). Ammonium salts in the frass were measured as ammonia in acid hydrolysates. Probability values are for contrasts between the fourth treatment group versus the other three treatment groups. Only damaged transgenic leaves produced elevated levels of ROS in larvae.

acid mixture. Contrary to the second hypothesis, there were no compensatory increases in the assimilation efficiencies of total amino acids by larvae on high-ROS-producing leaves (nor increases in waste nitrogen excretion). Finally, there was no support for the hypothesis that larvae compensate for a decreased supply of susceptible EAAs by increasing their absorption efficiencies for these EAAs. Such a physiological response, coupled with the depletion of susceptible EAAs in the midgut, would have caused significant decreases in the compositions of Arg, His, Lys, and/or Met in the midgut fluid and frass. Quantitative measurements of egested/ingested EAAs from larvae on high-ROS-producing leaves also showed little sign of decreases that would be consistent with ROS-EAA reactions and/or increased EAA absorption efficiency from the midgut. Based on these results, we are unable to reject the null hypothesis, suggesting that $L$. dispar larvae are able to tolerate high levels of ROS in their midguts without significant changes in the compositions of susceptible EAAs. Our results do not rule out the formation of reaction products between ROS and susceptible amino acids in vivo, but suggest that these reactions are not nutritionally significant in $L$. dispar on a wide range of host plants.

One important study has examined the interaction of ROS (quinones) with protein in vivo (Felton et al., 1989b). As much as $49 \%$ of the ingested labeled chlorogenic acid was bound to protein in the frass of two noctuid caterpillar species. This result suggested that quinones alkylated a large fraction of the susceptible amino acids, but changes in amino acid composition were not measured. Alternatively, it is possible that the proteins that remained undigested in the frass, such as peritrophic matrix proteins and polyphenol oxidase, acted as sinks for quinones. The alkylation of indigestible proteins would presumably have no significant nutritional cost. Compounds that function as sinks, if sufficiently reactive and concentrated, could help explain the ability of insect herbivores to protect themselves and their nutrients from damage by ROS. For example, the peritrophic membranes in caterpillars do act as "suicide antioxidants," reacting with ROS and protecting the midgut epithelium (Barbehenn and Stannard, 2004). Therefore, in contrast to in vitro reaction mixtures, ROS might react with many compounds in the midgut besides amino acids, which would diminish the observable effects on susceptable EAAs in vivo.

A potential limitation of this study was the lack of a phenolic-free leaf treatment. If the low levels of ROS produced by red oak and poplar leaves (phenolic treated) were sufficient to cause extensive reactions with susceptible EAAs, then the higher levels of ROS produced by sugar maple and induced POD-overexpressing poplar leaves might not 
have been able to react further with EAAs. On the other hand, the midgut fluid from L. dispar on poplar (untreated) was essentially ROS free (Barbehenn et al., 2009b), and yet no decreases in EAAs were observed when high levels of phenolic compounds oxidized in this midgut fluid ex vivo. A parsimonious interpretation of the consistent results across each of the three types of experiments is that there were no substantial losses of susceptible EAAs from reactions with ROS.

The results of this study suggest that high constitutive or induced levels of oxidative defenses (e.g., phenolics and POD) in tree leaves act on $L$. dispar by a mechanism other than antinutritional effects on EAAs in the midgut. Although elevated levels of ROS are associated with decreased growth rates, increases in ROS had no measurable effect on limiting EAAs in L. dispar. Toxicological mechanisms, such as oxidative stress, are known to occur in L. dispar on maple leaves (Barbehenn et al., 2009a), and might better explain the impact of ROS on this species on spring foliage.

Further work is needed to understand the factors that affect reactions of ROS in the midgut. For example, steric hindrance of protein-bound and peptide-bound amino acids appears to decrease reaction rates between ROS and EAAs (e.g., Fig. 2A and B). The role of antioxidant defenses in the protection and utilization of susceptible EAAs also deserves further attention. For example, methionine-sulfoxide reductase could play an important role in the utilization of oxidized Met by insect herbivores (e.g., Moskovitz et al., 2001). Additional in vivo and ex vivo studies in other plant-herbivore systems are needed to generalize about the importance of ROS for protein nutrition. We conclude that elevated levels of ROS, produced by phenolic oxidation in the midgut, do not necessarily cause nutritionally significant losses of susceptible EAAs in insect herbivores such as L. dispar.

\section{ACKNOWLEDGMENTS}

We thank Dr. Michael M. Martin for constructive criticism and the gift of tobacco leaf protein; Christine Lokerson (USDA) for L. dispar eggs; Austin Reese, Chris Dukatz, and Chris Holt for help with work on transgenic poplar trees; and Dr. Juha-Pekka Salminen for providing the ellagitannins. This project was supported by the National Research Initiative of the USDA Cooperative State Research, Education and Extension Service, grant numbers 2004-35302-14840 and 2007-35302-17803.

\section{LITERATURE CITED}

Awad HM, Boersma MG, Vervoort J, Rietjens IMCM. 2000. Peroxidase-catalyzed formation of quercetin quinone methide-glutathione adducts. Arch Biochem Biophys 378:224-233.

Barbehenn RV, Stannard J. 2004. Antioxidant defense of the midgut epithelium by the peritrophic envelope in caterpillars. J Insect Physiol 50:783-790.

Barbehenn RV, Bumgarner SL, Roosen E, Martin MM. 2001. Antioxidant defenses in caterpillars: role of the ascorbate recycling system in the midgut lumen. J Insect Physiol 47:349357.

Barbehenn RV, Cheek S, Gasperut A, Lister E, Maben R. 2005a. Phenolic compounds in red oak and sugar maple leaves have prooxidant activities in the midguts of Malacosoma disstria and Orgyia leucostigma caterpillars. J Chem Ecol 31:969-988.

Barbehenn R, Dodick T, Poopat U, Spencer B. 2005b. Fenton-type reactions and iron concentrations in the midgut fluids of tree-feeding caterpillars. Arch Insect Biochem Physiol 60:32-43. 
Barbehenn RV, Weir Q, Salminen J-P. 2008. Oxidation of ingested phenolics in the tree-feeding caterpillar Orgyia leucostigma depends on foliar chemical composition. J Chem Ecol 34:748756.

Barbehenn RV, Jaros A, Lee G, Mozola C,Weir Q, Salminen, J-P. 2009a. Tree resistance to Lymantria disparcaterpillars: importance and limitations of foliar tannin composition. Oecologia 159:777788 .

Barbehenn RV, Jaros A, Lee G, Mozola C, Weir Q, Salminen J-P. 2009b. Hydrolyzable tannins as "quantitative defenses": limited impact against Lymantria dispar caterpillars on hybrid poplar. J Insect Physiol 55:297-304.

Barbehenn R, Dukatz C, Holt C, Reese A, Martiskainen O, Salminen J-P, Yip L, Tran L, Constabel CP. 2010. Feeding on poplar leaves by caterpillars potentiates foliar peroxidase action in their guts and increases plant resistance. Oecologia 164:993-1004.

Broadway RM, Duffey SS. 1988. The effect of plant protein quality on insect digestive physiology and the toxicity of plant proteinase inhibitors. J Insect Physiol 34:1111-1117.

Byers M. 1971. Amino acid composition and in vitro digestibility of some protein fractions from three species of leaves of various ages. J Sci Food Agr 22:242-251.

Cohen SA, Michaud DP. 1983. Synthesis of a fluorescent derivatizing reagent, 6-aminoquinolyl-Nhyroxysuccinimidyl carbamate, and its application for the analysis of hydrolysate amino acids via high-performance liquid chromatography. Anal Biochem 211:279-287.

Felton GW. 1996. Nutritive quality of plant protein: sources of variation and insect herbivore responses. Arch Insect Biochem Physiol 32:107-130.

Felton GW, Duffey SS. 1990. Inactivation of baculovirus by quinones formed in insect-damaged plant tissues. J Chem Ecol 16:1221-1236.

Felton GW, Summers CB. 1995. Antioxidant systems in insects. Arch Insect Biochem Physiol 29:187197.

Felton GW, Broadway RM, Duffey SS. 1989a. Inactivation of protease inhibitor activity by plantderived quinones: complications for host-plant resistance against noctuid herbivores. J Insect Physiol 35:981-990.

Felton GW, Donato K, Delvecchio RJ, Duffey SS. 1989b. Activation of plant foliar oxidases by insect feeding reduces nutritive quality of foliage for noctuid herbivores. J Chem Ecol 15:2667-2694.

Felton GW, Donato KK, Broadway RM, Duffey SS. 1992. Impact of oxidized plant phenolics on the nutritional quality of dietary protein to a noctuid herbivore, Spodoptera exigua. J Insect Physiol 38:277-285.

Horie Y, Watanabe K. 1982. Evidence of stepwise digestion of protein in the digestive system of the silkworm, Bombyx mori (Lepidoptera: Bombycidae). Appl Ent Zool 17:358-363.

Horie Y, Watanabe K. 1983. Effect of various kinds of dietary protein and supplementation with limiting amino acids on growth, haemolymph components and uric acid excretion in the silkworm, Bombyx mori. J Insect Physiol 29:187-199.

Hurrell RF, Finot PA. 1984. Nutritional consequences of the reactions between proteins and oxidised polyphenolic acids. Adv Exper Med Biol 177:423-435.

Hurrell RF, Finot PA, Cuq JL. 1982. Protein-polyphenol reactions. British J Nutr 47:191-211.

Igarashi K, Yasui T. 1985. Oxidation of free methionine and methionine residues in protein involved in the browning reaction of phenolic compounds. Agr Biol Chem 49:2309-2315.

Johnson KS, Barbehenn RV. 2000. Oxygen levels in the gut lumens of herbivorous insects. J Insect Physiol 46:897-903.

Karowe DN, Martin MM. 1989. The effects of quantity and quality of diet nitrogen on the growth, efficiency of food utilization, nitrogen budget, and metabolic rate of fifth-instar Spodoptera eridania larvae (Lepidoptera: Noctuidae). J Insect Physiol 35:699-708.

Krishnan N, Kodrick D, Turanli F, Sehnal F. 2007. Stage-specific distribution of oxidative radicals and antioxidant enzymes in the midgut of Leptinotarsa decemlineata. J Insect Physiol 53:67-74. 
Liebhold AM, Gottschalk KW, Muzika R-M, Montgomery ME, Young R, O’Day K, Kelley B. 1995. Suitability of North American tree species to the gypsy moth: a summary of field and laboratory tests. United States Department of Agriculture Forest Service, Northeastern Forest Experimental Station, General Technical Report NE-211.

Lovett GM, Hart JE, Christenson LM, Jones CG. 1998. Caterpillar guts and ammonia volatilization: retention of nitrogen by gypsy moth larvae consuming oak foliage. Oecologia 117:513-516.

Matheis G, Whitaker JR. 1984. Modification of proteins by polyphenol oxidase and peroxidase and their products. J Food Biochem 8:137-162.

Mattson WA. 1980. Herbivory in relation to plant nitrogen content. Ann Rev Ecol Syst 11:19-38.

Moilanen J, Salminen J-P. 2008. Ecologically neglected tannins and their biologically relevant activity: chemical structures of plant ellagitannins reveal their in vitro oxidative activity at high $\mathrm{pH}$. Chemoecology 12:203-211.

Moskovitz J, Bar-Noy S, Williams WM, Requena J, Berlett BS, Stadtman ER. 2001. Methionine sulfoxide reductase (MsrA) is a regulator of antioxidant defense and lifespan in mammals. Proc Nat Acad Sci 98:12920-12925.

Pierpoint WS. 1983. Reactions of phenolic compounds with proteins, and their relevance to the production of leaf protein. In: Telek L, Graham HD, editors. Leaf protein concentrates. Westport, CT: Avi Publishing Co. p 235-267.

Quideau S, Feldman KS, Appel HM. 1995. Chemistry of galloyl-derived o-quinones: reactivity toward nucleophiles. J Org Chem 60:4982-4983.

Rock GC. 1972. Optimal proportions of dietary amino acids. In: Rodriguez JG, editor. Insect and mite nutrition. Amsterdam: North-Holland Publishing Co. p 183-197.

SAS Institute. 2003. The SAS system for Windows. Version 9.1. Cary, NC: SAS Institute.

Schilling S, Sigolotto C-S, Carle R, Schieber A. 2008. Characterization of covalent addition products of chlorogenic acid quinone with amino acid derivatives in model systems and apple juice high-performance liquid chromatography/electrospray ionization tandem mass spectrometry. Rapid Comm Mass Spec 22:441-448.

Sheen SJ. 1991. Comparison of chemical and functional properties of soluble leaf proteins from four plant species. J Agr Food Chem 39:681-685.

Shinbo H, Konno K, Hirayama C, Watanabe K. 1996. Digestive sites of dietary proteins and absorptive sites of amino acids along the midgut of the silkworm, Bombyx mori. J Insect Physiol 42:11291138.

Shingfield KJ, Offer NW. 1999. Simultaneous determination of purine metabolites, creatine and pseudouridine in ruminant urine by reversed-phase high performance liquid chromatography. J Chrom Sci 723:81-94.

Strydom DJ, Cohen SA. 1993. Sensitive analysis of cystine/cysteine using 6-aminoquinolyl-Nhydroxysuccinimidyl carbamate (AQC) derivatives. In: Angeletti RH, editor. Techniques in protein chemistry IV. San Diego: Academic Press. p 299-306.

Wolfersberger MG. 2000. Amino acid transport in insects. Annu Rev Entomol 45:111-120.

Yeoh H-H, Wee Y-C, Watson L. 1992. Leaf protein contents and amino acid patterns of dicotoledonous plants. Biochem Syst Ecol 20:657-663.

van Zyl L, Ferreira AV. 2003. Amino acid requirements of springbok (Antidorcas marsupialis), blesbok (Damaliscus dorcas phillipsi) and impala (Aepyceros melampus) estimated by the whole empty body essential amino acid profile. Small Ruminant Res 47:145-153. 